\title{
Examining the strings of our violins whilst Rome is burning: A rebuttal
}

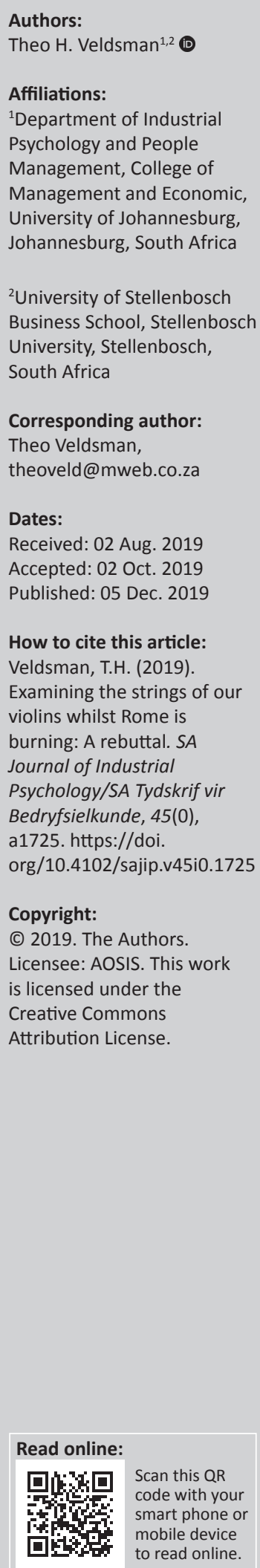

Problemification: In response to the admirable objective of Efendic and Van Zyl's (2019) article to offer recommendations to address the crisis of replication in industrial organisational psychology (IOP), I offer the counter-argument that this immediate crisis, although important, is of lesser importance in the greater scheme of the challenges faced by IOP, going into the future. It is merely symptomatic of a deeper and greater illness in IOP.

Implications: I contend that the 'lesser' crisis of replication pales into insignificance against the backdrop of three accelerating and snowballing, interacting meta-crises within IOP: (1) growing irrelevance (= a burning Rome), (2) an outdated, constraining research paradigm (= an antiquated violin) and (3) ill, even toxic, research community dynamics and functioning (= our stressed-out violinists).

Purpose: The aim of my rebuttal is to elucidate the three meta-crises and point out their lifethreatening implications for IOP going into the future. Future-fit responses to address these meta-crises are offered.

Recommendations: Given these meta-crises, going forward in building the academic reputation of the South African Journal of Industrial Psychology (SAJIP), a number of recommendations are made regarding making SAJIP future-proof (= fit-for-purpose, firefighting violins and violinists).

Keywords: industrial organisational psychology; meta-crises; relevancy; research paradigm; research community dynamics and functioning.

\section{Introduction}

The admirable objective of Efendic and Van Zyl's (2019) article is to stimulate an open dialogue amongst the stakeholders of the South African Journal of Industrial Psychology (SAJIP) regarding the replication crisis in psychology in general - and industrial organisational psychology (IOP) specifically - in order to take the journal to the next level of academic excellence. The authors elucidate what they suggest are easily implementable improvements related to open-science practices, as well as research methodological and editorial enhancements.

The weight of their well-thought and well-argued recommendations centres on:

1. procedural and statistical solutions to be complied with by researchers in conducting their research

2. quality assurance criteria (or means) to be applied by the SAJIP editorial board to submitted articles to ensure replicability.

The authors' quest is for greater credibility and transparency in conducting and disseminating IOP research in SAJIP.

\section{My vantage point and the accelerating and snowballing, interacting meta-crises within industrial organisational psychology going into the future}

The vantage point of my rebuttal is that science is a social enterprise, practised (= playing the violin) by researchers (= the violinists) as knowledge workers - mostly academics at universities - aimed at making a relevant, lasting, worthy difference (= the music) in a context (= Rome). Given this vantage point, my rebuttal to Efendic and Van Zyl's (2019) focus on the crisis of replication in IOP with their commensurate recommendations is to offer the counter-argument 
that this 'immediate' crisis, although important, is less important in the greater scheme of the challenges faced by IOP, going into the future.

I would like to submit that, on the one hand, in many ways the replication crisis is merely a symptom of a deeper dysfunctionality in the practice of our science. On the other hand, this crisis pales in significance to other greater meta-crises faced by IOP. Metaphorically, we are examining the strings (= how we do science) of our violins whilst Rome is burning.

I would like to approach my rebuttal by addressing three accelerating and snowballing, interacting meta-crises within IOP, which I believe override the 'lesser' crisis of replication, which I contend is more of a symptom of the meta-crises discussed below:

1. growing irrelevance (= a burning Rome)

2. an outdated, constraining research paradigm (= an antiquated violin)

3. ill, even toxic, research community dynamics and functioning (= our stressed-out violinists).

I wish to conclude my rebuttal with some recommendations that can be considered by the stakeholders of the SAJIP in facing up to these greater meta-crises. The essence of my recommendations revolves around the challenge to make the journal future-ready for the emerging, new order. In particular, to the emerging, new world of work whose decision-makers I would submit the journal aspires to serve by reporting on timely, relevant, credible IOP research findings.

\section{The meta-crisis of growing irrelevance}

The world as we know it, including the world of work, is changing in radical and fundamental ways at an accelerating pace. Rome as we know it presently is burning furiously. Figure 1 provides an overview of the emerging, new order in terms of substantive trends, contextual qualities represented by the world of Variety, Interdependency, Complexity, Change, Ambiguity and Seamlessness (VICCAS), emerging success criteria and its 'competitive maths'. All of the aforesaid give rise to a 'recalibrated' competitive equation for organisations (Veldsman, 2019b).

As depicted in Figure 1, the emerging, new order requires organisations to rethink radically from first principles the why?, what?, how?, who?, where? and where to? of their business, not only in the present but also in particular whilst engaging with the significantly different future of the emerging, new order. Playing fields, game plans, players and rules have to be re-invented from the zero base.

In particular, I wish to specify four, interdependent major forces of change in greater detail as reflected in Figure 1 (Veldsman, 2019b):

- Qualitatively, the VICCAS (an extension of VUCA: Volatile, Uncertain, Complex, Ambiguous) world. The world is moving towards complicated contexts of unknown knowns to complex contexts of unknown unknowns and even chaotic contexts of unknowables (Kurtz \& Snowden, 2003).

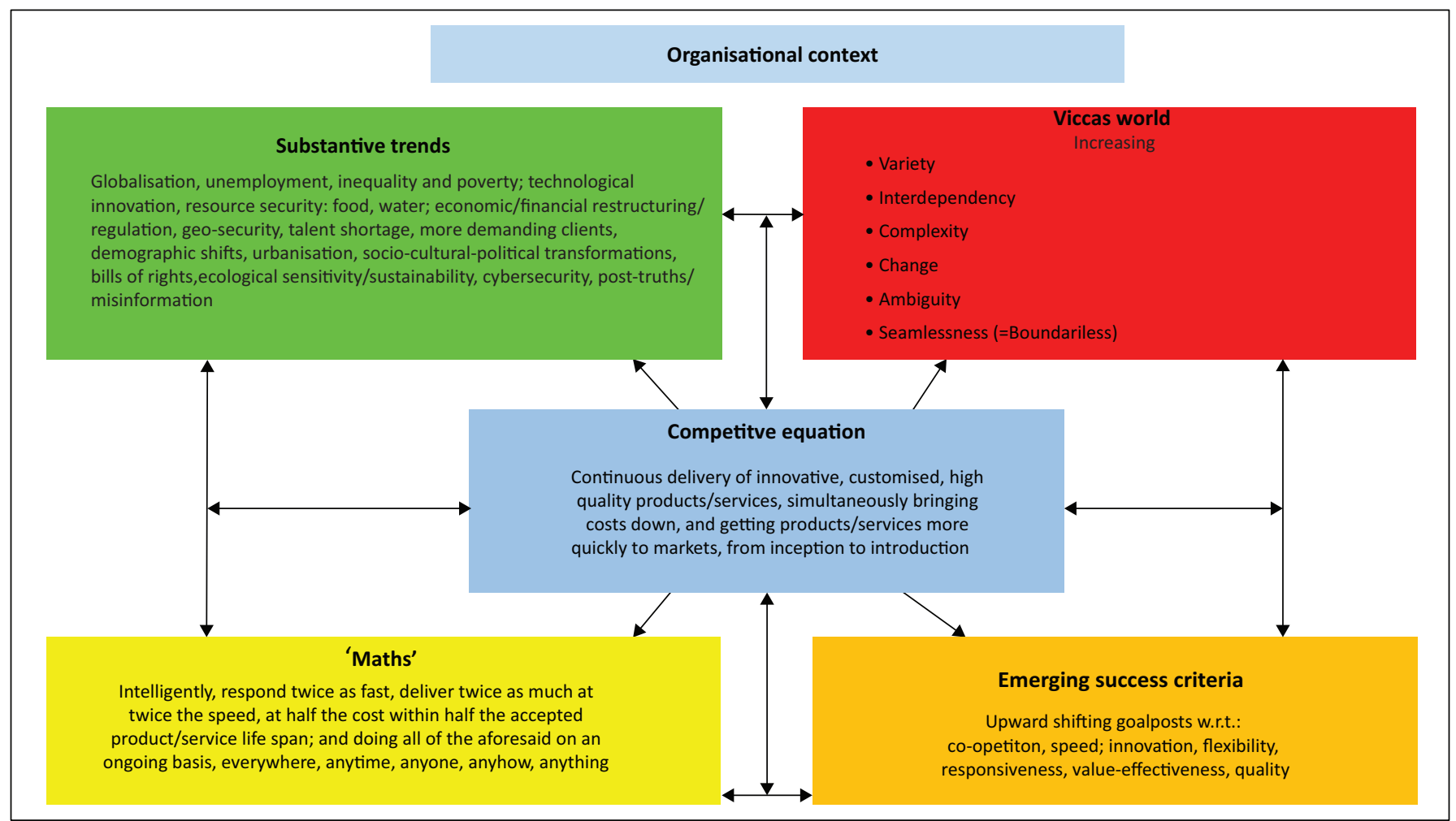

FIGURE 1: Emerging, new order. 
- Exponentially, accelerating technological innovation, encapsulated in the term 'Fourth Industrial Revolution'. This revolution can be represented by the acronym, DIVAS: Digitisation, Interconnectivity, Virtualisation, Automation, and Smart (= Intelligence).

- The growing adoption - sometimes enforced - of the core value orientation of sustainability through stewardship through pressure on organisations to become genuine social citizens: leaving the world a better place for current and upcoming generations.

- An ever-extending, increasingly diverse range of activist stakeholders with shifting interest, demands and expectations - frequently in conflict, demanding tradeoffs - whose growingly strident voices are amplified significantly by the social media, enabling their rapid mobilisation around issues, nationally and globally.

The above-described order has invoked the consequential, merciless imperative of relentless, ongoing, disruptive (even destructive) innovation as the critical strategic, renewal success factor for organisations, communities, nations and societies wanting to remain future-ready and future-fit. That is, not merely to survive but also to thrive into the future. This imperative demands looking at everything afresh from first principles, seeing the impossible as possible, finding new answers to questions, even more so asking totally, new questions and regarding nothing as untouchable, unchangeable or re-imaginable. In all respects, we are being forced back to zero-base and first principles.

In turn, the relentless, ongoing disruptive innovation has invoked the necessity of continuous deep relearning, learning and unlearning by all at all times in all places. If individuals, organisations, communities and societies do not learn (L), and re-invent themselves faster than the rate of change (C), they will not have a future because they would have become obsolete. To thrive and stay ahead of the game, $\mathrm{L}>\mathrm{C}$.

I would suggest that the above-described, emerging new order, specifically the world of work, places the total body of knowledge and practice of IOP under contention: what is relevant (read, valid) or not in and for the emerging, new order? Additionally, what is totally new and requires research to make us relevant in this order? For example, the challenge of virtuous, people-technology optimised integration within the Fourth Industrial Revolution (Veldsman, 2019a). Even more critical is, how should we reframe our research in terms of the new mind sets of working in radically, different ways, imposed by the emerging, new order?

Our stake to enable evidence-based decision-making in practice is under significant threat. But, even more pressing is our ability to supply such evidences timely, and not always to be in a catch-up situation where practice is ahead of us. How do we move in our research faster than the rate of change in the world of work? The burning question is how do we conduct IOP research regarding a hyperfluid and hyperturbulent world of work infused by Complicated
Contexts of Unknown Knowns, Complex Contexts of Unknown Unknowns and even Chaotic Contexts of Unknowables?

I would like to contend that we are living a pipedream in believing that we as IOPs can proactively and timeously deliver such evidences through our conventional research paradigm, approaches, processes and practices (see the further discussion below). It is estimated that at present $65 \%$ of all new knowledge is being generated outside of universities, the primary home of academics. The world we wish to serve is moving much faster for IOP, except if we are able to address successfully the other two meta-crises discussed below. However, I am more pessimistic about whether we have the genuine will to address, given our entrenched, institutional ways of doing things deeply entrenched by well-protected, vested interests.

This is in spite of me being fully committed in my unwavering belief that IOP as science-practice must make a lasting, worthy difference in practice. But then, how? For me, the essence of the solution is that we have to rethink and reimagine IOP as science-practice, similar to what organisations have to do in the emerging, new order, completely and fundamentally. The real danger and risk are that the vacuum of our presence in the world of work will be filled up speedily by others, especially within the throes of the Fourth Industrial Revolution by the likes of engineers and IT scientists (Ones, Kaiser, Chamorro-Premuzic \& Svensson, 2017). We will be shunted to the sideline, and will be seen as endangered dinosaurs living in fiercely, self-protected reserves.

\section{The meta-crisis of an outdated, constraining research paradigm}

I would like to raise three manifestations of this meta-crisis which I believe are at the root of IOP's continued existence or not, as a difference-making science-practice: firstly, an obsolete worldview framing our thinking, and particularly our research; secondly, an inadequate research design paradigm, given the pace of change; and, thirdly, our fetish and fanaticism to quantify everything: if something is not measureable, it does not exist. Meta-theoretically, the ruling IOP beliefs and assumptions have become mismatched to the world we research, and we wish to make a difference to and in. Our violins have become inappropriate to the music we need to compose and make.

Generally speaking, IOP research, and is reinforced by academic journals as gatekeepers, firstly, is dominated by an antecedent-moderator-outcome research paradigm, reflective of a Mechanistic (or Newtonian) worldview of reality. In this worldview, reality is seen as being the sum total of its parts, interacting linearly, striving for homeostasis (Bal, 2019).

It is strongly argued that this worldview has become totally obsolete, and is not at all a true reflection of the nature of reality. It is argued that a truer worldview of reality is a complexity (or chaos) perspective: viewing reality 
organically, systemically and holistically as a set(s) of nonlinearly interacting variables configuring themselves in selfdesigning patterns, whether virtuous or vicious, going through unpredictable states of order and chaos (Boulton, Allen \& Bowman, 2015; Veldsman, 2016, 2019a).

It is ironic that psychology, which has been accused in the past of uncritically adopting the worldview of the natural sciences in its endeavour to be accepted as a 'true' science, has stuck to the outdated mechanistic worldview underlying yesteryear natural sciences. To date, Psychology in general has not adopted a complexity (or chaos) worldview underlying quantum physics reflective of the 'new' natural sciences (cf. Wheatley, 2010).

From the outset then, by implication, IOP's existing research paradigm is framing its research within an antiquated worldview. We are producing evidence based on a dated, wrongly framed reality. No wonder prospective users of our research view our theories and research findings as reality estranged because they do not resonate with the complexity (or chaos) reality they engage with every day as practitioners. Their world does not work linearly. However, there are encouraging signs that some areas in IOP, such as leadership, are adopting a complexity (or chaos) worldview (cf. Uhl-Bien \& Marion, 2008).

Secondly, the ruling, conventional verification research design paradigm - 'Closeted in our offices, painstakingly prove something is true over many years of rigorous hypotheses testing, before accepting and disseminating' (Theo $\mathrm{H}$. Veldsman, location unknown, date unknown) - is producing research-based evidence much too slowly for the pace at which the emerging, world order and our practice are moving. As discussed above, in the emerging, new order, learning has to occur faster than the rate of change in order not to become extinct. This is why many organisations are now building their own people research capabilities and analytics, matching with the emerging, new order's pace of change as reflected in the $65 \%$ new knowledge produced outside universities as quoted above.

We have to replace, or at least complement, our conventional research paradigm with one that is more attuned to the pace this order is moving. For example, a falsification research design paradigm - 'Accept that a theory is true and use it in practice, until evidence to the contrary surfaces during its application, requiring its adaptation'. In close, real-time partnership with related academic disciplines and outside organisations, craft practice-attuned research processes and methodologies like action research and learning - that are able to generate evidence-based, immediately usable knowledge, rapidly. (Of course, the challenge of replicability addressed by Efendic and Van Zyl [2019] remains regardless of the research paradigm adopted.)

Thirdly, our institutionalised fanaticism to quantify everything. If something cannot be quantified, it does not matter. But as
Albert Einstein said, ' $[n]$ ot everything that matters can be measured' (source unknown). Einstein did not conduct a single piece of empirical research himself in his life time but through his Thinking Experiments - resulting in his (special) relativity theory - reframed our thinking completely about the universe (Isaacson, 2007). Some of his theorising is being proven even 100 years after it was proposed, like the existence of cosmic gravity waves recently. Analogous to Einstein's Thinking Experiments, a dire need exists in IOP for thinking experiments regarding a reimagined world of work, given the emerging, new order discussed above. Sophisticated quantification of the 10 th decimal place is not going to get us there.

The reinforcement of the above-elucidated, outdated, constraining research paradigm because of the dynamics and functioning of our research community (see below) and the constraining gate-keeping role of academic journals especially exemplary, high-ranking journals in our field - is placing the relevancy of IOP at a significant risk where it truly matters. In a study reported on a couple years back in The Economist, it was found that paradigm-busting thinking and research - for example, von Bertalanffy's proposed open systems theory - generally do not get accepted for publication in mainstream journals at first, but are rather published in 'side stream' journals (source unknown).

\section{The meta-crisis of ill, even toxic, research community dynamics and functioning}

Science is practised in a research community made up of people, functioning according to (self-imposed) common ideals, beliefs, processes and standards, and interacting according to shared, internalised, even imposed, traditions, norms and values (= violinists). The dysfunctionality of the (IOP) research community resident at and across universities has been well documented (Bal et al., 2019).

The relentless pressure of 'publish or perish' to be granted tenure, achieve promotional and career aspirations, gain scarce research grants and meet institutionally imposed, performance goals, fuelled by the merciless pursuit of creeping up the globally rankings by universities, have a number of detrimental effects (cf. Bal et al., 2019; Byington \& Felps, 2017; Edwards \& Roy, 2016; Ones et al., 2017; Veldsman, 2019c, Efendic \& Van Zyl, 2019):

- Academics being imprisoned in their solipsistic, impregnable, institutional universe, chasing and producing research of ever-increasing miniscule topics that bear little relevance to societal challenges, issues and problems. They pursue safe, low-risk research topics with short turnaround times in a self-serving manner. Many leading South African people practitioners have 'complained' to me that in looking at the table of contents of leading IOP journals, both local and global studies, they find little relevance. Those (few) articles that appear to be relevant to them, are academically and statically so obtuse that they 
give up in despair in trying to make sense of them. The statistical wizardry is beyond them. IOP is becoming increasingly precise in ways that matter increasingly less, particularly in practice (Ones et al., 2017).

- Researchers unethically adjust research designs, processes and results in order to get published (the primary focus of Efendic \& Van Zyl, 2019).

- The erosion of the academic integrity and ethos of universities through plagiarism, predatory journals, bogus research and fake articles corrupt the total credibility of the scientific enterprise commensurate with with an undermining of public trust.

- Universities become 'publication clearing houses', only serving their own, narrow institutional interests in their fanatic, self-centred pursuit of ever, higher global rankings. The external world with its challenges, demands and issues passes by them as representing annoying and interfering noise and detraction. Mission-critical is rather improving the institution's global ranking.

- All the above undermine the well-being of academics and (post-graduate) students.

Proposals that are similar to Efendic and Van Zyl (2019), such as predominately procedural and statistical solutions to be complied with by researchers in conducting their research and quality assurance criteria (or means) to be applied by the Editorial Board of SAJIP to submitted articles to ensure high research standards such as replicability, are merely addressing to my mind the symptoms of the greater, underlying systemic ill and toxicity in the research community dynamics and functioning as outlined above. In a sense, their recommendations may even worsen the mounting pressures on academics by imposing even more, burdensome, self referencing, research processes and standards, having been already hijacked by trivial statistical minutiae.

The systemic root causes of these symptoms rather have to be addressed. Raising the statistical and methodological bars will not solve the symptoms. Some of the micro, remedial actions may be:

1. Asking what are the $20 \%$ research requirements that make $80 \%$ of the difference in research quality, instead of the uncompromising pursuit of the unattainable Holy Grail of 'perfect' research.

2. Related to the previous point, adopt the agile, business concept of a 'minimum viable product' in which a product meeting minimum requirements is released and progressively enhanced through later releases. When applied to research, this supports the notion of the progressive enhancement of research evidence with respect to an area through successive minimum viable research evidence.

3. The intense, uncompromising indoctrination and training of students and young researchers in research ethics and standards, and minimum research requirements, concurrently infused by a burning passion to make a lasting, worthy difference where it truly matters through their research.
4. Having practice-orientated academic journals publishing research that matters in practice.

Of course, macro, institutional interventions will also have to be affected, which is beyond the scope of this rebuttal (see also Bal et al., 2019 in this regard).

\section{Going forward: Building the academic reputation of South African Journal of Industrial Psychology}

Against the above exposition, the following recommendations appear appropriate regarding making SAJIP future-proof (= fit-for-purpose, fire-fighting violins and violinists) (see also, e.g., Byington \& Felps, 2017; Ones et al., 2017):

- Ensure an Editorial Board composed of both academics and leading practitioners, meeting at least annually to debate the direction, focus and policy of the journal. The Article Review Committee must also be made up of academics and practitioners.

- Choose a niche in which the Journal wants to become THE source of research evidence. My suggestion would be emerging economies, like BRICS, of which it is expected that China and India will be become the dominant, world economies by 2030. The Journal can focus in particular on Africa as upcoming continent.

- Identify as research topics the practice-related challenges or burning issues within the journal's chosen niche. Invite and give articles on these challenges or issues preference. Even sponsor such research.

- Framed by a complexity (or chaos) world view, encourage and accept a diversity of research paradigms and designs: meta-theoretical (including underlying ideologies), as well as scientific and practice orientated research, using both verification and falsification research process designs, seeking explanation and understanding, exploration and confirmation, all reflective of the total IOP sciencepractitioner spectrum.

- Set and publically communicate minimum acceptable research quality requirements and standards with respect to the research based on the different research paradigms and designs. 'Applify' the quality requirements and standards such that researchers can 'stress test' themselves their articles' compliance in a self-corrective manner on line before submission.

- Transform the article review process into a three-way, iterative learning process from the research proposal through to the final article between researchers, reviewers (both academics and practitioners) and editor, similar to dissertation committees within the US university system.

\section{Acknowledgements Competing interests}

The author declares that they have no financial or personal relationships which may have inappropriately influenced them in writing this article. 


\section{Author's contributions}

T.H.V. is the sole author of this research article.

\section{Ethical considerations}

This article followed all ethical standards for a research without direct contact with human or animal subjects.

\section{Funding information}

This research received no specific grant from any funding agency in the public, commercial or not-for-profit sectors.

\section{Data availability statement}

Data sharing is not applicable to this article as no new data were created or analysed in this study.

\section{Disclaimer}

The views and opinions expressed in this article are those of the author and do not necessarily reflect the official policy or position of any affiliated agency of the author.

\section{References}

Bal, P.M. (2019). The future of work and organisational psychology - A working session. IOP 4.0, 2019 SIOPSA Conference, 23 July 2019, Pretoria.
Bal, P.M., Dóci, E., Lub, X., Van Rossenberg, Y.G.T., Nijs, S., Achnak, S., ... Van Zelst, M. (2019). Manifesto for the future of work and organizational psychology. European Journal of Work and Organizational Psychology, 28(3), 289-299. https://doi.org/ Journal of Work and Organizational

Boulton, J.G., Allen, P.M., \& Bowman, C. (2015). Embracing complexity. Strategic perspectives for an age of turbulence. Oxford: Oxford University Press.

Byington, E.K., \& Felps, W. (2017). Solutions to the credibility crisis in management science. Academy of Management Learning \& Education, 16(1), 142-162. https:// doi.org/10.5465/amle.2015.0035

Edwards, M.A., \& Roy, S. (2016). Academic research in the 21st century: Maintaining scientific integrity in a climate of perverse incentives and hypercompetition. Environmental Engineering Science, 00(00), 1-11. https://doi.org/10.1089/ees. 2016.0223

Efendic, E., \& Van Zyl, L.E. (2019). On reproducibility and replicability: Arguing for open practices and methodological improvements at the South African Journal of Industrial Psychology. South African Journal of Industrial Psychology, 45(0), a1607. https://doi.org/10.4102/sajip.v45i0.1607

Isaacson, W. (2007). Einstein. His life and universe. London: Simon \& Schuster.

Kurtz, C., \& Snowden, D.J. (2003). The new dynamics of strategy: Sense-making in a complex and complicated world. IBM Systems Journal, 42, 462-483. https://doi. org/10.1147/sj.423.0462

Ones, D.S., Kaiser, R.B., Chamorro-Premuzic, T., \& Svensson, C. (2017). Has industrialorganizational psychology lost its way? TIP: The Industrial-Organizational Psychologist, 54(4), 67-74.

Uhl-Bien, M., \& Marion, R. (Eds.). (2008). Complexity leadership. Part 1: Conceptual foundations. Place of publication unknown: Information Age Publishing.

Veldsman, T.H. (2016). Leadership engagement with the context. In T.H. Veldsman \& A.J. Johnson (Eds.). Leadership. Perspectives from the front line (pp. 325-340). Johannesburg: Kr Publishing.

Veldsman, T.H. (2019a). Designing fit-for-purpose organisations. A comprehensive, integrated rout map. Johannesburg: $\mathrm{Kr}$ Publishing.

Veldsman, T.H. (2019b). Organisational design in the fourth industrial revolution. Challenge of virtuous, people-technology optimised integration. Johannesburg, unpublished Public Lecture at the University of Johannesburg, Johannesburg, 4 June 2019.

Veldsman, T.H. (2019c). Higher education institutions need to face up to the future. (28 June-4 July 2019), Mail \& Guardian, 31-32.

Wheatley, M.J. (2010). Leadership and the new science: Discovering order in a chaotic world. San Francisco, CA: Berrett-Koehler. 